\title{
Silica Fume and Nanosilica Effects on Mechanical and Shrinkage Properties of Foam Concrete for Structural Application
}

\author{
Jianqing Gong $\mathbb{D},{ }^{1}$ Lilin $\mathrm{Zhu}\left(\mathbb{D},{ }^{1}\right.$ Jiusu $\mathrm{Li}^{2}$, and Da Shi $\mathbb{D}^{1}$ \\ ${ }^{1}$ College of Civil Engineering, Hunan University, Changsha, Hunan 410082, China \\ ${ }^{2}$ School of Traffic and Transportation Engineering, Changsha University of Science \& Technology, 410114 Changsha, China
}

Correspondence should be addressed to Jianqing Gong; gongjianqing@hnu.edu.cn

Received 7 January 2020; Revised 15 March 2020; Accepted 24 March 2020; Published 27 April 2020

Academic Editor: Paweł Kłosowski

Copyright ( $\odot 2020$ Jianqing Gong et al. This is an open access article distributed under the Creative Commons Attribution License, which permits unrestricted use, distribution, and reproduction in any medium, provided the original work is properly cited.

Adding the appropriate amount of silica fume (SF) or nanosilica (NS) can improve the strength and reduce the shrinkage of foam concrete (FC), thereby widening its application. This paper reports on a study of FC mechanical and shrinkage properties when varying SF and NS proportions were used to replace cement. Scanning electron microscopy (SEM) and nonmetallic ultrasonic detection were employed to investigate the mechanism of strength changes. The result showed that when the SF and NS content was $15 \%$ and $4 \%$, in the 28 days, the compressive strength of FC peaked at $32.8 \mathrm{MPa}$ and $35.8 \mathrm{MPa}$, and the flexural strength maximized at 7.9 MPa and $9.1 \mathrm{MPa}$, respectively. The autogenous shrinkage reached the minimum value, separately, i.e., $741.2 \times 10^{-6}$ and $797.1 \times 10^{-6}$. The dry shrinkage value was the highest $\left(862.5 \times 10^{-6}\right.$ and $\left.1387.5 \times 10^{-6}\right)$. The results indicated that the compressive and flexural strength of FC first increased and then decreased as SF and NS content increased. Autogenous shrinkage first decreased and then increased with the increase of SF or NS content. An opposite trend of dry shrinkage could be observed. FC made with NS had higher shrinkage than it did with SF. The results also indicated that there was a correlation between microstructure and sound velocity in the presence of SF or NS.

\section{Introduction}

Nowadays, foam concrete (FC) has attracted more and more attention. FC is an economical and environmentally friendly material [1]. It is light and possesses acceptable thermal insulation and low elasticity $[2,3]$. It absorbs shocks and has acceptable fire resistance [4]. It is currently widely used in civilian, underground, and municipal engineering and sports construction and the military [5]. But its shortcomings are low strength and high shrinkage [6], which limit its application. Therefore, improving FC strength and reducing its shrinkage can help widen FC application.

Contemporary research into FC mechanical and shrinkage properties has primarily concentrated on nonstructural FC. Nambiar and Ramamurthy [7] reported on how various aggregates influenced FC properties. As aggregate sand grain size decreased, FC strength increased. Kearsleya and Wainwright $[8,9]$ studied fly ash (FA) content effects on FC strength. When FA replaced more than $67 \%$ of the cement, compressive strength decreased significantly.
Nambiar and Ramamurthy [10-12] examined the influence of stomatal characteristics on FC density and compressive strength. Stomatal apertures and spacing between pores influenced FC density and strength. As stomatal distribution and pore diameter distribution uniformed, intensity increased. Stomatal shape had little effect on the intensity. Jones and McCarthy [13] reported the effects of untreated low-calcium FA on FC properties and found it had an acceptable strength. Kearsley and Wainwright $[14,15]$ discovered that FC pore structure closely relates to strength, water absorption, and dry shrinkage. Hou et al. [16] found that adding a proper amount of nanoparticles in foaming agent and precast foam can improve the mechanical properties of foamed concrete. He et al. [17] found that the size and distribution of pores have a great influence on physical and mechanical properties. Nguyen et al. [18] studied the effects of pore characteristics and mortar properties on the mechanical properties of FC by micromechanics. Falliano and et al. [19] studied factors influencing compressive strength of FC, for example, dry density, 
moisture content, curing conditions, cement type, and foaming agent type. Sun et al. [20] studied the effects of different foaming agents on dry shrinkage of FC.

Little research has been done on FC for structural applications. Bing et al. [21] determined that high-strength FC with a density range of $1000 \sim 1500 \mathrm{~kg} / \mathrm{m}^{3}$ and compressive strength of approximately 20 50 MPa could be obtained by using SF, polypropylene fiber, and a high-efficiency water reducer. Kearsley and Wainwright $[8,9]$ developed a sandfree, high-strength FC with a low water-binder ratio using SF and FA. Jones and McCarthy [22] studied the influence of FA on high-strength FC performance by substituting cement, or fine aggregate, for FA. Those substitutions significantly improved FC performance.

Higher shrinkage [23] of FC than ordinary concrete has been a critical barrier for the past seven decades. Wan et al. [24] verified that the shrinkage of FC with a dry density of $1500 \mathrm{~kg} / \mathrm{m}^{3}$ approximately equaled that of the ordinary concrete. The shrinkage of FC with a dry density of $1600 \mathrm{~kg} / \mathrm{m}^{3}$ increased with the increase of the amount of polyvinyl alcohol (PVA) fiber [25]. The shrinkage of FC with a density of $1600 \mathrm{~kg} / \mathrm{m}^{3}$ could be reduced efficiently by incorporating propylene glycol (PG), triethylene glycol (TEG), and dipropylene glycol tert-butyl ether (DPTE) [26]. However, rare research has been carried out to compare NS and SF on FC strength or to investigate their influence on shrinkage.

This paper reports on a study of using mechanical tests, shrinkage tests, scanning electron microscopy (SEM), and ultrasonic nondestructive tests to compare FC mechanical and shrinkage properties, hydration products, and micromorphology of FC using different dosages of SF and NS. The potential application of FC in the presence of SF or NS for structural elements was analyzed and discussed.

\section{Materials and Methods}

2.1. Materials. Ordinary Portland Cement 42.5 produced by Hunan South Cement Plant was used. Its chemical composition and basic performance indexes were given in $\mathrm{Ta}$ ble 1 and Table 2. Quartz sand produced by Heyuan Wanchuan Quartz Development Limited Company, with a 40-70 mesh size and density of $2.65 \mathrm{~g} / \mathrm{cm}^{3}$, was used. Its grading curve was given in Figure 1. SF produced by Shanxi Yizhou Ferroalloy Factory, with an average particle diameter ranging from 0.1 to 0.3 microns and density of $2.2 \mathrm{~g} / \mathrm{cm}^{3}$, was used. Its chemical composition was given in Table 3. NS produced by Shanghai Yuanjiang Chemical Limited Company, with a diameter of $30 \mathrm{~nm}$ and a density of $2.2 \mathrm{~g} / \mathrm{cm}^{3}$, was used. Grade I FA produced by Henan Sitong Chemical Construction Limited Company, with a density of $2.6 \mathrm{~g} / \mathrm{cm}^{3}$, was used. Its chemical composition was given in Table 4 . Lime powder with a density of $1.2 \mathrm{~g} / \mathrm{cm}^{3}$ was used and its composition was given in Table 5. A polycarboxylic acid superplasticizer (water-reducing rate: $31 \%$ ) produced by Nanjing Sitaibao Company, with a density of $500 \mathrm{~g} / \mathrm{L}$, was used. A foaming agent (vegetable protein anionic surfactant) produced by Guangdong Yunfu Qingzhou Cement Limited Company, with a density of $1.01 \mathrm{~g} / \mathrm{L}$, was used to induce foam.
TABle 1: Cement chemical composition.

\begin{tabular}{llllllll}
\hline Composition & $\mathrm{SiO}_{2}$ & $\mathrm{Al}_{2} \mathrm{O}_{3}$ & $\mathrm{MgO}$ & $\mathrm{CaO}$ & $\mathrm{Fe}_{2} \mathrm{O}_{3}$ & $\mathrm{SO}_{3}$ & Others \\
\hline
\end{tabular}

\begin{tabular}{llllllll}
\hline Content (\%) & 21.88 & 4.49 & 2.36 & 64.65 & 3.45 & 2.44 & 0.73 \\
\hline
\end{tabular}

2.2. Mix Proportion. An orthogonal test was carried out on the mix proportion of FC with a dry density of $1600 \mathrm{~kg} / \mathrm{m}^{3}$. The influence of various factors on FC strength was investigated. The optimum mix proportion was determined through range analysis. The factors and levels of the orthogonal test were selected as shown in Table 6. The optimum mix proportion and strength were shown in Table 7.

This study examined and analyzed the impact of varying percentages of SF $(0 ; 5 ; 10 ; 15 ; 20 ; 25)$ and NS $(0 ; 1$; $2 ; 3 ; 4 ; 5)$ on FC flexural strength, compressive strength, elastic modulus, autogenous shrinkage, and drying shrinkage. FC, with a density of $1600 \mathrm{~kg} / \mathrm{m}^{3}$, can be made by using (1) varying percentages of SF and NS; (2) a waterbinder ratio of 0.22 ; (3) a sand-cement ratio of 1.0 ; (4) an FA ratio of 25\%; (5) a lime powder ratio of $2 \%$; (6) a water reducing agent ratio of $1 \%$. The difference between adding SF and NS into FC was also analyzed. The mix proportion appears in Table 8.

2.3. Test Methods. The flexural and compressive strength and elastic modulus were evaluated in accordance with the specification in China (GB/T 11969-2008 [27]). The sample sizes for compressive strength and flexural strength were $100 \mathrm{~mm} \times 100 \mathrm{~mm} \times 100 \mathrm{~mm}$ and $100 \mathrm{~mm} \times 100 \mathrm{~mm}$ $\times 400 \mathrm{~mm}$, respectively. Sample size for elastic modulus was $100 \mathrm{~mm} \times 100 \mathrm{~mm} \times 300 \mathrm{~mm}$. A method of combination of noncontact probes and corrugated pipes was used to test the autogenous shrinkage. The pipes were $340 \pm 5 \mathrm{~mm}$ long, with inner and outer diameters of $20 \mathrm{~mm}$ and $30 \mathrm{~mm}$, respectively. Each test group had two test samples. A mean value of autogenous shrinkage for the two samples was adopted for each group. The dry shrinkage was determined in accordance with JGJ/T70-2009 [28]. Each group had three $40 \mathrm{~mm} \times 40 \mathrm{~mm} \times 160 \mathrm{~mm}$ samples. Comparator (SP-175) was used to measure the length of samples at $0,3,7,14,21$, 28 , and 56 days. SEM (JSM-649LV) was used to detect the microstructure of FC. Nonmetallic ultrasonic nondestructive testing equipment (ZBL-V520) was used to measure the ultrasound speed of FC in accordance with ASTM C597-02 [29].

\section{Results and Discussion}

\subsection{Mechanical Properties}

3.1.1. Compressive Strength. As shown in Figure 2, FC compressive strength initially increased and then decreased as SF or NS ratios increased. As SF ratios increased from $0 \%$ to $15 \%$ and NS ratios increased from $0 \%$ to $4 \%$, FC compressive strength at 7 and 28 days gradually increased. FC compressive strength at 7 and 28 days reached its highest level of $21.7 \mathrm{MPa}$ and $32.8 \mathrm{MPa}$ when SF was $15 \%$ whereas it was $24.9 \mathrm{MPa}$ and $35.8 \mathrm{MPa}$ when $4 \% \mathrm{NS}$ was 
TABle 2: Cement basic index.

\begin{tabular}{lccccccc}
\hline \multirow{2}{*}{ Cement } & \multirow{2}{*}{ Density $\left(\mathrm{g} / \mathrm{cm}^{3}\right)$} & \multicolumn{3}{c}{ Compressive strength $(\mathrm{MPa})$} & \multicolumn{3}{c}{ Flexural strength (MPa) } \\
& & 3 days & 7 days & 28 days & 3 days & 7 days & 28 days \\
\hline P.O. 42.5 & 3.15 & 29.4 & 38.5 & 47.6 & 6.2 & 7.5 & 9.9 \\
\hline
\end{tabular}

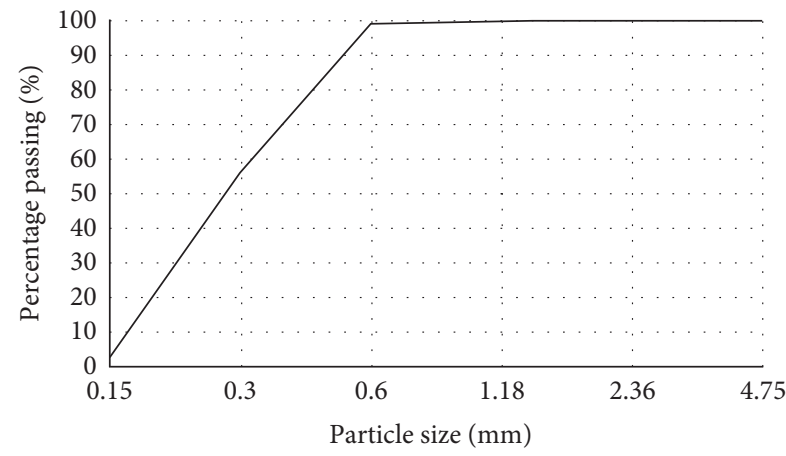

Figure 1: Grading curve of quartz sand.

TABLE 3: SF chemical composition.

\begin{tabular}{lllllllll}
\hline Composition & $\mathrm{SiO}_{2}$ & $\mathrm{~K}_{2} \mathrm{O}$ & $\mathrm{Fe}_{2} \mathrm{O}_{3}$ & $\mathrm{MgO}$ & $\mathrm{CaO}$ & $\mathrm{NaO}$ & $\mathrm{C}$ & Loss \\
\hline
\end{tabular}

\begin{tabular}{lllllllll} 
Content (\%) & 93.9 & 0.85 & 0.58 & 0.27 & 1.86 & 0.17 & 1.07 & 2.25 \\
\hline
\end{tabular}

TABLE 4: FA chemical composition.

\begin{tabular}{lcccccc}
\hline Composition & $\mathrm{SiO}_{2}$ & $\mathrm{Al}_{2} \mathrm{O}_{3}$ & $\mathrm{Fe}_{2} \mathrm{O}_{3}$ & $\mathrm{CaO}$ & $\mathrm{MgO}$ & $\mathrm{SO}_{3}$ \\
\hline Content (\%) & $20 \sim 62$ & $10 \sim 40$ & $3 \sim 19$ & $1 \sim 45$ & $0.2 \sim 5$ & $0.02 \sim 4$ \\
\hline
\end{tabular}

TABLE 5: Lime powder chemical composition.

\begin{tabular}{lcccccc}
\hline Composition & $\mathrm{CaO}$ & $\mathrm{SiO}_{2}$ & $\mathrm{Al}_{2} \mathrm{O}_{3}$ & $\mathrm{Fe}_{2} \mathrm{O}_{3}$ & $\mathrm{MgO}$ & Loss \\
\hline Content (\%) & 46.25 & 12.82 & 1.61 & 1.08 & 0.64 & 36.86 \\
\hline
\end{tabular}

TABLE 6: Orthogonal test factors and levels.

\begin{tabular}{lcccc}
\hline Factors & Water-binder ratio & Sand-cement ratio & FA & Lime \\
\hline 1 & 0.18 & 0.8 & $15 \%$ & 1.0 \\
2 & 0.22 & 1.0 & $20 \%$ & 1.5 \\
3 & 0.26 & 1.2 & $25 \%$ & 2.0 \\
\hline
\end{tabular}

blended. Generally, the micro- or nanoparticles in SF or NS may densify greatly the FC mortar. Additionally, secondary hydration of SF or NS improves strength radically [30]. However, at $4 \%$ NS, FC compressive strength at 7 and 28 days was $14.7 \%$ and $9.1 \%$ higher than $15 \%$ SF. This can be attributable to the much smaller particle size and higher specific surface area of NS, which enables NS to hydrate vigorously, and the resulting hydration products efficiently densify FC mortar [31]. FC compressive strength decreased as SF exceeded $15 \%$ and NS exceeded $4 \%$. There are two possible reasons. First, the foam in FC intends to collapse and merge in the presence of excessive SF or NS which may weaken the compressive strength of FC. Second, the increased water absorption of SF or NS inhibits the hydration.

3.1.2. Flexural Strength. Figure 3 shows the influence of SF and NS ratios on FC flexural strength. FC flexural strength shows a similar pattern with compressive strength. When SF and NS percentages increased from $0 \%$ to $15 \%$ and $0 \%$ to $4 \%$, respectively, FC flexural strength at 7 and 28 days gradually increased. FC flexural strength at 7 and 28 days reached the highest level of $6.6 \mathrm{MPa}$ and $8.7 \mathrm{MPa}$ when SF was $15 \%$ and $7.0 \mathrm{MPa}$ and $9.1 \mathrm{MPa}$ when NS was $4 \%$. At $4 \%$ NS, FC flexural strength at 7 and 28 days was $6.1 \%$ and $4.6 \%$ higher than $15 \%$ SF. When the added amount of SF and NS was more than $15 \%$ and $4 \%$, the flexural strength decreased.

3.1.3. Elastic Modulus. Elastic modulus is an important parameter for designing FC in structural elements. As mentioned above, the compressive strength and flexural strength of FC peaked when SF and NS content was $15 \%$ and $4 \%$, respectively. The elastic modulus of FC was measured when the optimum SF or NS content was blended. In the presence of $15 \%$ SF or $4 \%$ NS, the elastic modulus of FC was $18.5 \mathrm{GPa}$ and $19.4 \mathrm{GPa}$, respectively. Investigation on the elastic modulus of foam concrete, with a similar strength grade of $30 \mathrm{MPa}$ to $35 \mathrm{MPa}$, has rarely been reported. However, the results indicated an obvious $E_{\mathrm{FC}}$ increase when compared to the ordinary foam concrete [32,33]. When compared to lightweight concrete in the same strength grade range, obvious elastic modulus difference, that is, $2.5 \mathrm{GPa}$ to $5.5 \mathrm{GPa}$, could also be found [34-36].

According to JGJ 51-2002 [37], LC15 lightweight aggregate concrete is allowed for load-bearing components or structures building. The corresponding elastic modulus is $11.6 \mathrm{GPa}$ when the apparent density and strength grade are $1600 \mathrm{~kg} / \mathrm{m}^{3}$ and $15 \mathrm{MPa}$, respectively. Consequently, the manufactured foam concrete, whether it is blending with SF or NS, characterized with a compressive strength of $32.8 \mathrm{MPa}$ or $35.8 \mathrm{MPa}$, and elastic modulus of $18.5 \mathrm{GPa}$ or $19.4 \mathrm{GPa}$, respectively, can be recommended for potential structural application.

\subsection{Shrinkage}

3.2.1. Autogenous Shrinkage. Figure 4 shows the changes in FC autogenous shrinkage over time, under different SF and NS ratio conditions. As time passed, FC autogenous shrinkage values increased rapidly from 0 to $24 \mathrm{~h}$. They remained stable after $24 \mathrm{~h}$.

When SF increased from $0 \%$ to $15 \%, \mathrm{FC}$ autogenous shrinkage decreased. When $15 \% \mathrm{SF}$ was added, after $72 \mathrm{~h}, \mathrm{FC}$ 
TABLE 7: Optimal mix proportion and strength.

\begin{tabular}{|c|c|c|c|c|c|c|c|}
\hline \multirow[t]{2}{*}{ Water-binder ratio } & \multirow[t]{2}{*}{ Sand-cement ratio } & \multirow[t]{2}{*}{ FA } & \multirow[t]{2}{*}{ Lime (\%) } & \multicolumn{2}{|c|}{$\begin{array}{l}\text { Compressive strength } \\
(\mathrm{MPa})\end{array}$} & \multicolumn{2}{|c|}{$\begin{array}{l}\text { Flexural strength } \\
(\mathrm{MPa})\end{array}$} \\
\hline & & & & 7 days & 28 days & 7 days & 28 days \\
\hline 0.22 & 1.0 & $25 \%$ & 2.0 & 17.7 & 26.9 & 5.1 & 7.0 \\
\hline
\end{tabular}

TABle 8: Mix proportion design (unit: $\mathrm{kg} / \mathrm{m}^{3}$ ).

\begin{tabular}{lcccccccccc}
\hline Group & Cement & FA & SF & NS & Lime powder & Quartz sand & Water & Foam & Water reducer & Fresh density \\
\hline$A 0$ & 520.56 & 178.27 & 0.00 & - & 14.26 & 713.09 & 156.88 & 16.94 & 7.13 & 1589 \\
$A 1$ & 484.90 & 178.27 & 35.65 & - & 14.26 & 713.09 & 156.88 & 16.94 & 7.13 & 1597 \\
$A 2$ & 449.25 & 178.27 & 71.31 & - & 14.26 & 713.09 & 156.88 & 16.94 & 7.13 & 1622 \\
A3 & 413.59 & 178.27 & 106.96 & - & 14.26 & 713.09 & 156.88 & 16.94 & 7.13 & 1617 \\
$A 4$ & 377.94 & 178.27 & 142.62 & - & 14.26 & 713.09 & 156.88 & 16.94 & 7.13 & 1608 \\
$A 5$ & 342.28 & 178.27 & 178.27 & - & 14.26 & 713.09 & 156.88 & 16.94 & 7.13 & 1627 \\
$B 1$ & 513.42 & 178.27 & - & 7.13 & 14.26 & 713.09 & 156.88 & 16.94 & 7.13 & 1604 \\
$B 2$ & 506.29 & 178.27 & - & 14.26 & 14.26 & 713.09 & 156.88 & 16.94 & 7.13 & 1596 \\
$B 3$ & 499.16 & 178.27 & - & 21.39 & 14.26 & 713.09 & 156.88 & 16.94 & 7.13 & 1608 \\
$B 4$ & 492.03 & 178.27 & - & 28.52 & 14.26 & 713.09 & 156.88 & 16.94 & 7.13 & 1619 \\
$B 5$ & 484.90 & 178.27 & - & 35.65 & 14.26 & 713.09 & 156.88 & 16.94 & 7.13 & 1592 \\
\hline
\end{tabular}

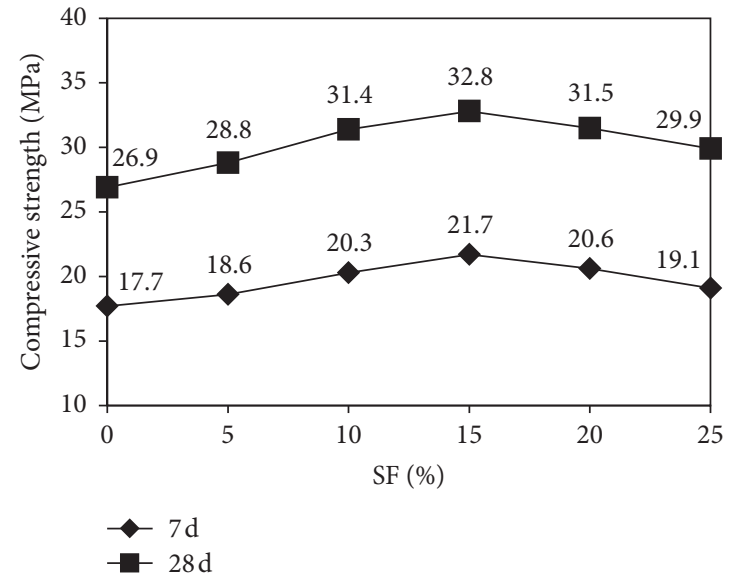

(a)

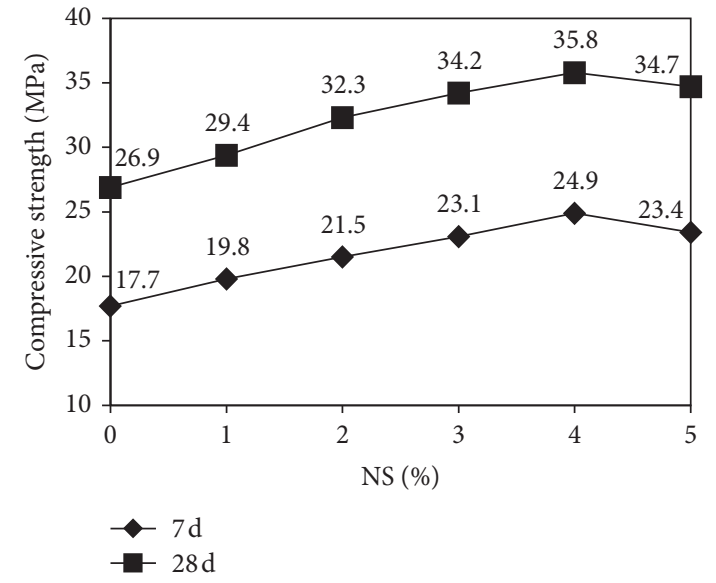

(b)

Figure 2: FC compressive strength.

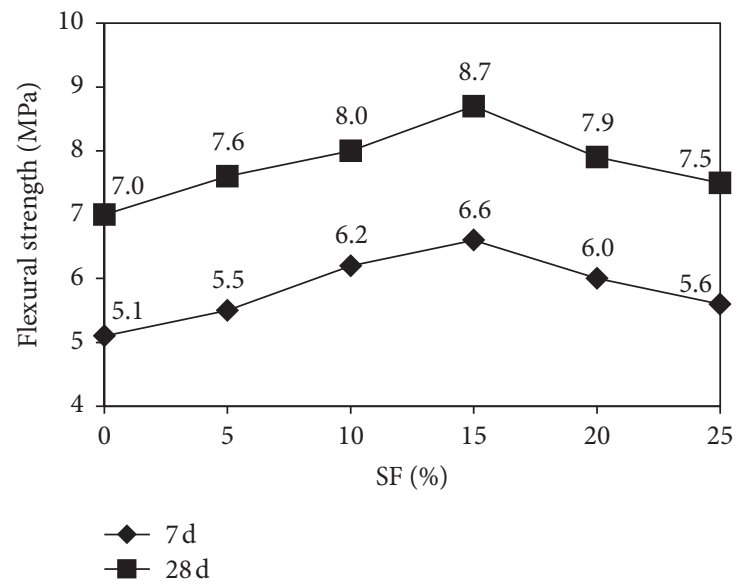

(a)

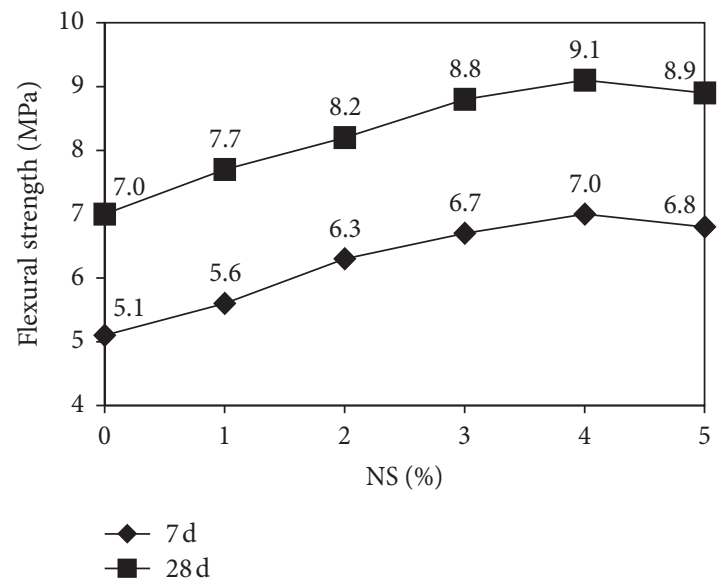

(b)

FIgURE 3: FC flexural strength. 


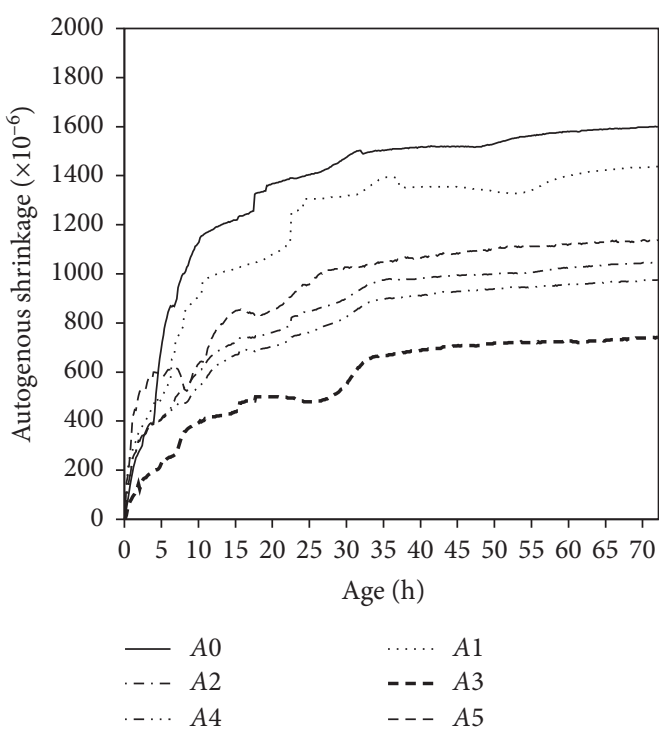

(a)

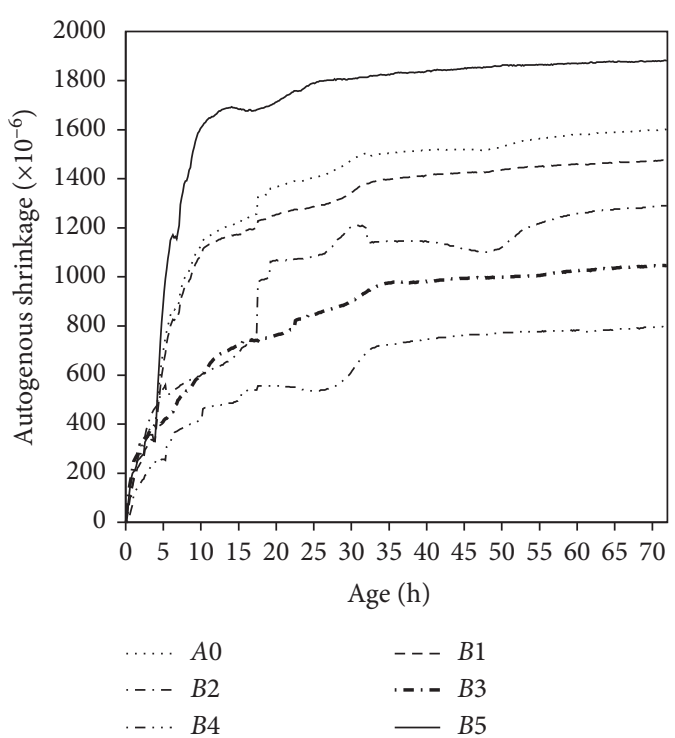

(b)

FIgURE 4: FC autogenous shrinkage.

autogenous shrinkage was $53.7 \%$ lower than when SF was absent. FC strength may develop rapidly when SF is added [38], which results in higher strength and stiffness and strong resistance to autogenous shrinkage. The law of strength corresponds well with that of a contraction driving force. The strength growth rate was higher than that of capillary negative pressure [39], which limited contraction.

When SF increased from $15 \%$ to $25 \%$, FC autogenous shrinkage values increased. The reasons may be that, first, SF particles are fine and their filling properties refine FC pore structure; second, early stage-generated $\mathrm{Ca}(\mathrm{OH})_{2}$ is scattered and small. After adding SF, it easily reacts with SF to form hydrated calcium silicate with a low $\mathrm{C} / \mathrm{S}$ ratio. This makes the interface between unhydrated cement particles and hydrated calcium silicate more compact and uniform [40]. Third, when SF quantities are high, excess SF continues to react with the C-S-H to generate an outer layer of hydrated calcium silicate which has a lower $C / S$ ratio. This makes the SF cement base material structure more compact [41]. SF reduces FC porosity and average pore diameter. The autogenous shrinkage is related to FC capillary pressure. Capillary pressure is mainly related to diameter. More SF results in smaller capillary diameters, higher capillary pressure, and greater $\mathrm{FC}$ autogenous shrinkage.

As NS increased from $0 \%$ to $4 \%$, FC autogenous shrinkage gradually decreased. At $4 \%$ NS dosage, after $72 \mathrm{~h}$, it was $50.2 \%$ lower than the virgin FC without SF. And it was $7.5 \%$ higher when compared to FC in the presence of $15 \%$ $\mathrm{SF}$. The reason for the decrease of autogenous shrinkage is similar to SF. Due to the higher specific area, NS has a negative effect on FC autogenous shrinkage when compared to SF.

3.2.2. Dry Shrinkage. Figure 5 shows the change in FC dry shrinkage values over time under different SF and NS quantities. As time elapses, FC dry shrinkage values increase rapidly from 0 to 14 days but remain stable after 14 days.

When FC amounts increased from $0 \%$ to $15 \%$, FC dry shrinkage values increased. At $15 \%$ SF, FC dry shrinkage values after 56 days increased $68.3 \%$ more than FC which lacked SF. FC dry shrinkage values increased as SF quantity increased for the following reasons. First, SF is highly active and can accelerate early FC hydration reaction. Rapid internal water consumption leads to an early FC capillary tension growth rate. Growth rates increased as $\mathrm{SF}$ amounts increased causing great early shrinkage [42]. Secondly, SF requires large amounts of water. As SF increases, slurry fluidity decreases and a large number of cement particles clump into groups. During mixing, foam deformation and bursting are likely to occur. After hardening, the structure is not dense, the internal defects are increased, and there are many pores connected, which are prone to dry shrinkage.

As SF increased from $15 \%$ to $25 \%$, FC dry shrinkage values decreased because excessive SF led to the nonhydration of some other SF particles. SF particles are very fine and effectively fill the pores between concrete particles which improves FC particle gradation and compacts the structure while reducing dry shrinkage values. This plays a dominant role when the quantity of SF is high.

As NS increased from $0 \%$ to $4 \%$, FC dry shrinkage increased. After 56 days, dry shrinkage of FC with $4 \%$ NS was $170.7 \%$ higher than non-NS FC and $60.9 \%$ higher than FC with $15 \%$ SF. The cause of FC with NS dry shrinkage first increase was similar to that of FC with SF. FC had a larger dry shrinkage value when NS was added compared to SF because NS particles are smaller, have a larger specific surface area, hydrate more completely, and have a quicker internal water consumption compared to SF. This results in increasing FC dry shrinkage. FC dry shrinkage value was decreased with extra NS similar to that of SF. 


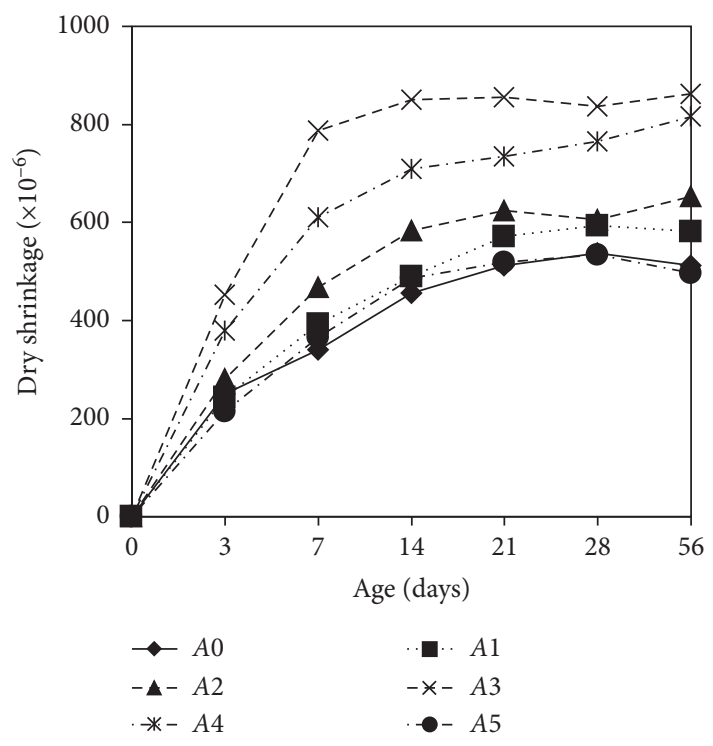

(a)

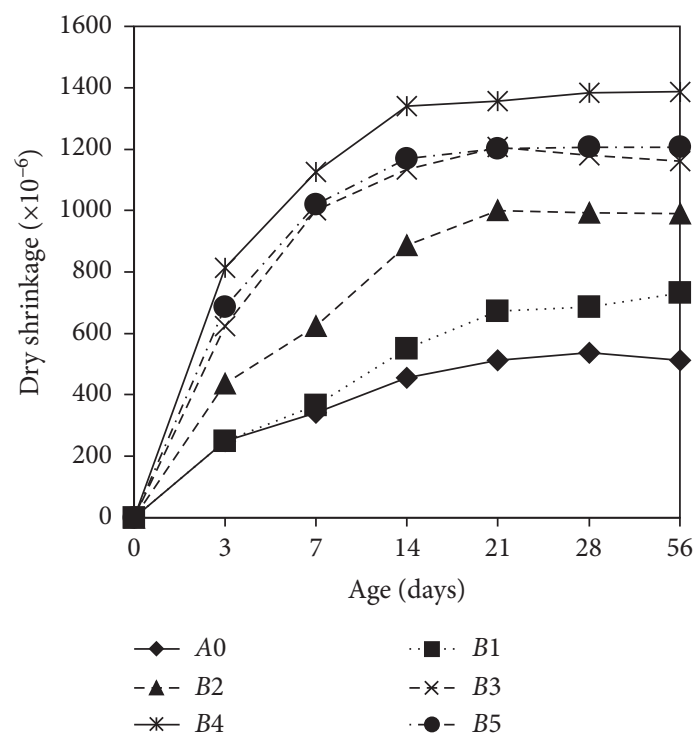

(b)

Figure 5: FC dry shrinkage.

3.3. Microstructure. SEM was used to observe the resulting FC microstructure of different quantities of SF (5\%, 15\%, and $25 \%)$ and NS (1\%, $4 \%$, and $5 \%)$.

3.3.1. FC with Added NS. Figure 6 shows FC microstructures under different percentages of NS (1\%; 4\%; 5\%).

The 50x magnification figures in Figure 6 show that FC with $4 \%$ NS had the smallest pore diameter, minimum interconnected pores, and the lowest breaking rate, whereas FC blended with $1 \%$ and 5\% NS had larger pore diameters, more interconnected pores, and higher breaking rates. The filling effect of NS can improve FC pore structure. But excessive NS may cause foam to burst, causing the FC pore size, the number of interconnected pores, and pore breakage rates to increase. Therefore, adding NS to FC in a certain amount can improve pore structure and strength.

The 5000x magnification figures in Figure 6 reveal that, compared to FC with $1 \%$ and $5 \%$ NS, FC with $4 \%$ NS had fewer unhydrated particles and flaky calcium hydroxide. It had more C-S-H gels, a denser ettringite, and a more compact structure. At 10,000x magnification (Figure 6) the ettringite in FC with 4\% NS was more compact than in either FC with $1 \%$ or $5 \%$ NS. This indicated that a certain amount of NS may promote cement hydration, while excessive NS may increase water absorption and restrict hydration reactions. Flake calcium hydroxide is quite brittle structurally and FC strength reduced due to that. NS can partially, or wholly, consume the calcium hydroxide generated by the cement hydration products. It will generate C-S-H in order to make full use of cement and increase concrete internal structural compactness and improve concrete strength [43]. As a result, the strength of FC with $4 \% \mathrm{NS}$ was greater than either FC with $1 \%$ or $5 \%$ NS. Therefore, FC with $4 \%$ NS had the most efficient microstructure and the highest strength.
3.3.2. Comparison between NS and SF. Figure 7 presents the microscopic structure of FC mortar when 5\%, 15\%, and 25\% SF was blended, respectively. It showed that when 15\% SF was used, the lowest porosity, minimum interconnected pores, and the lowest breaking rate in FC could be observed. More C-S-H gels, fewer unhydrated particles, and flaky calcium hydroxide could be found. In addition, more densified microstructure also occurred in SEM. Thus, the strength peaked in the presence of $15 \%$ SF.

Compared to the FC with 4\% NS shown in Figure 6, FC with $15 \%$ SF had larger pore diameters, more interconnected pores, more unhydrated particles, less ettringite, fewer C-S$\mathrm{H}$ gels, and a less compact structure because NS particles are finer than SF particles and can more efficiently fill FC pore structures. NS particles can make the pore structure more compact and the pore size distribution more uniform. NS has a larger specific surface area than SF, which may make the reaction more effective. Therefore, FC with $4 \%$ NS is stronger than FC with $15 \%$ NS.

3.4. Relationship between Ultrasonic Speed and FC Strength. Nonmetallic ultrasonic testing equipment measures FC for SF at $0 \% ; 5 \% ; 10 \% ; 15 \% ; 20 \% ; 25 \%$ and for NS at $0 \% ; 1 \% ; 2 \%$; $3 \% ; 4 \% ; 5 \%$. Measurement results appear in Figure 8.

Figure 8 shows that FC ultrasonic speed first increased and then decreased as SF and NS amounts increased. FC ultrasonic speed reached its highest levels for $15 \%$ SF and $4 \%$ NS. This may be due to the fact that when a small amount of SF is added to FC, the cement slurry becomes well covered by foam, making the pore diameter distribution more uniform and decreasing average pore diameter which, in turn, decreases porosity. However, when additional SF is present, the extra SF is not completely hydrated via cement hydration products. This may burst some foam structures 

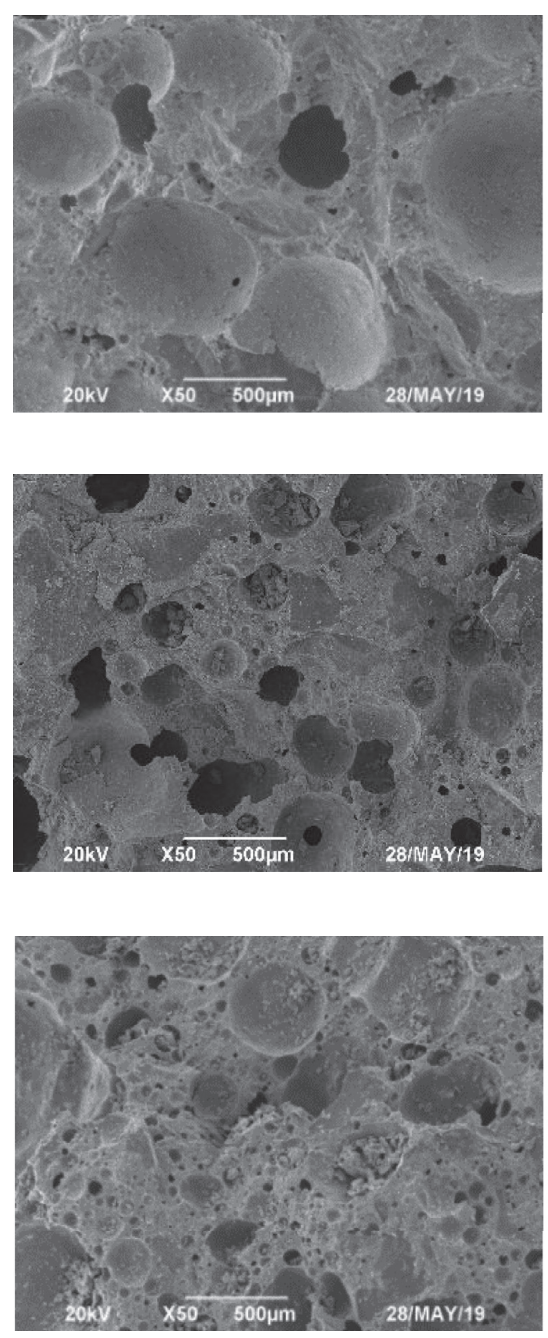

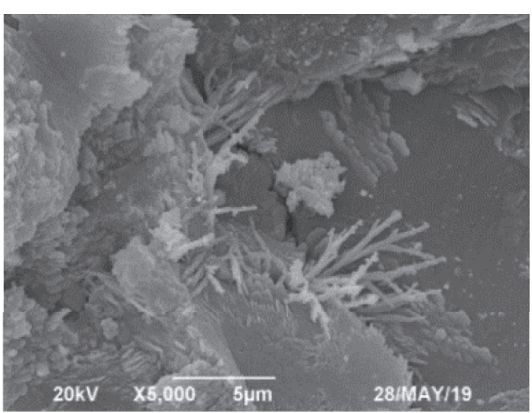

(a)
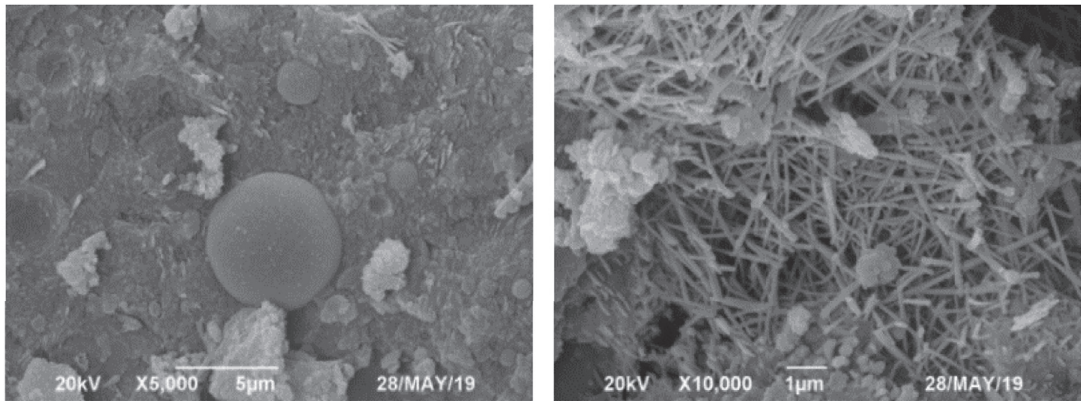

(b)
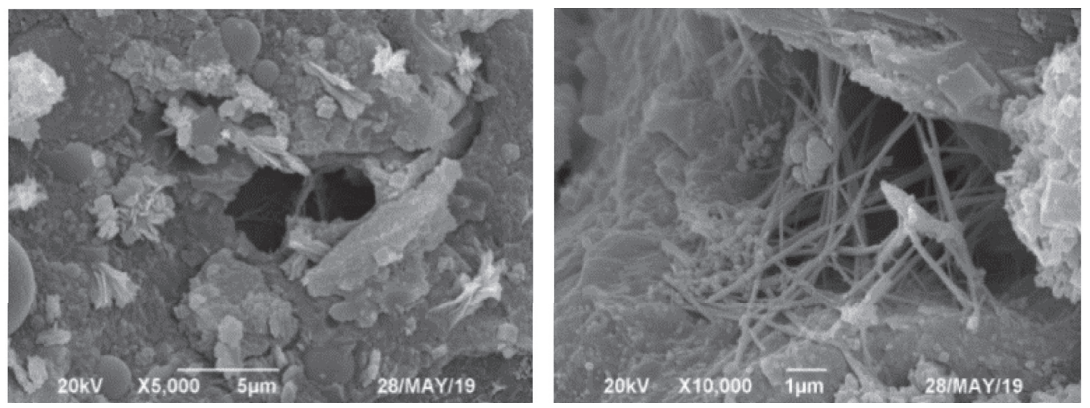

(c)

Figure 6: FC microstructures under SEM: (a) 1\% NS; (b) 4\% NS; (c) 5\% NS.

and increase capillary pores leading to a decrease in ultrasonic speed.

The ultrasonic speed of FC with $15 \%$ SF increased by $16.7 \%$ compared to non-SF FC. While FC with $4 \%$ NS increased by $27.3 \%$ as compared to non-NS FC, FC with $4 \%$ NS increased by $9.1 \%$ compared to FC with $15 \%$ SF. The results suggest the rule of change for FC strength and ultrasonic sound is the same. FC ultrasonic speed increases as FC strength increases and vice versa.

\section{Conclusion}

Improving the strength and reducing the shrinkage are critical for the potential structural application of FC. The influence of SF and NS on strength and shrinkage was investigated and compared in detail. SF and NS, in varying amounts, were measured and compared in terms of their mechanical properties, shrinkage properties, microstructure, and ultrasonic velocity with the following results and conclusions.
(1) The compressive strength of FC peaked at $35.8 \mathrm{MPa}$ and $32.8 \mathrm{MPa}$, when $4 \% \mathrm{NS}$ or $15 \% \mathrm{SF}$ was blended, indicating that it was a potential alternative for structural cases. The shrinkage was higher than that of ordinary concrete but acceptable.

(2) FC flexural and compressive strength increased at first and then decreased as SF, or NS, was added. When SF and NS were $15 \%$ and $4 \%$, respectively, FC compressive and flexural strength maximized. The amount of NS added, as of this moment, was $73.3 \%$ less than SF, but the resulting strength was higher compared to when FC was added to SF.

(3) FC autogenous shrinkage value decreased at first and then increased as SF, or NS, was added. FC dry shrinkage value increased at first and then decreased as SF, or NS, increased. FC shrinkage was larger in FC with $4 \%$ NS than FC with $15 \%$ SF.

(4) FC microstructures vary depending upon the quantity of NS or SF added. Stronger FC was 

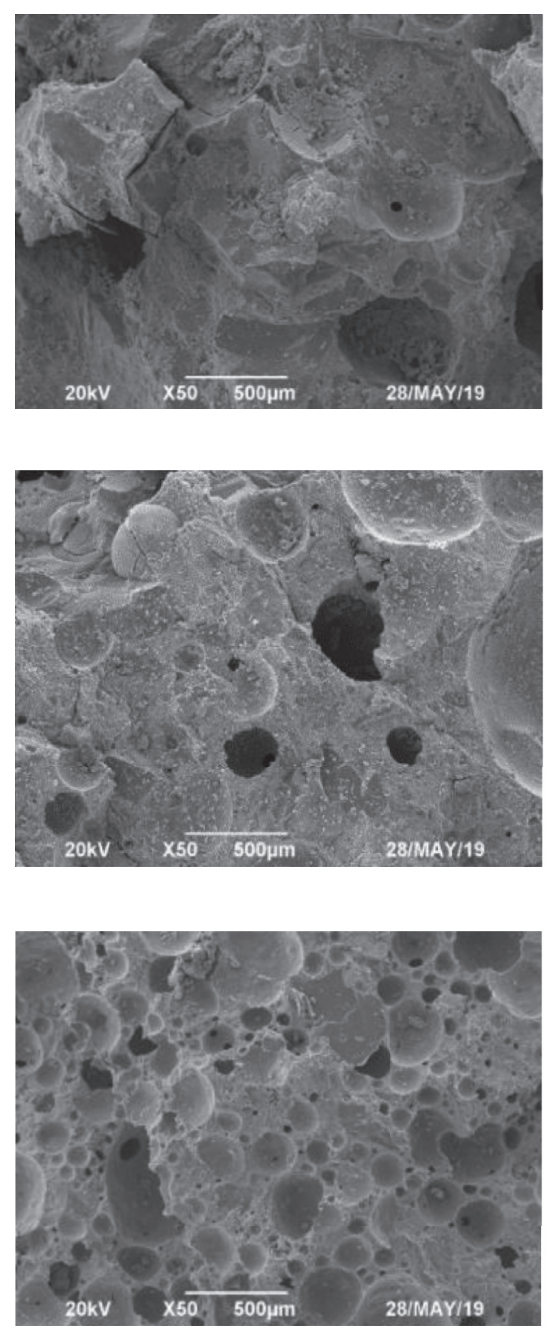

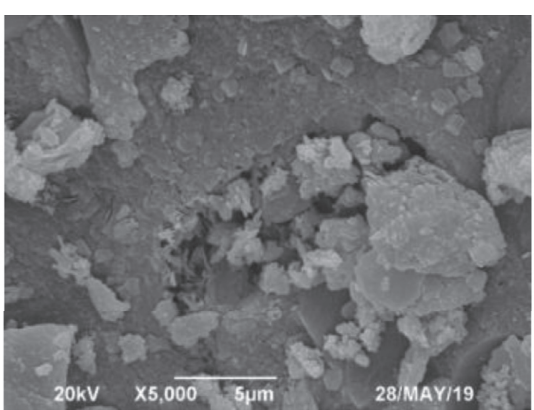

(a)

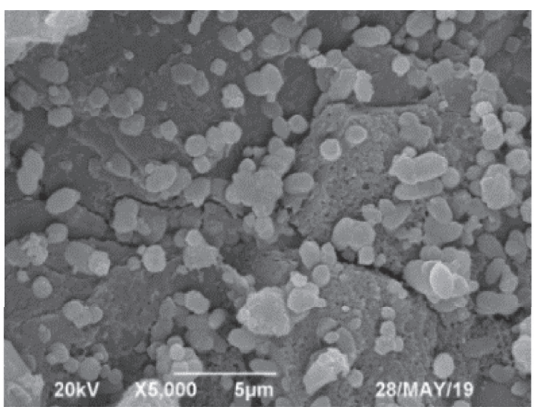

(b)

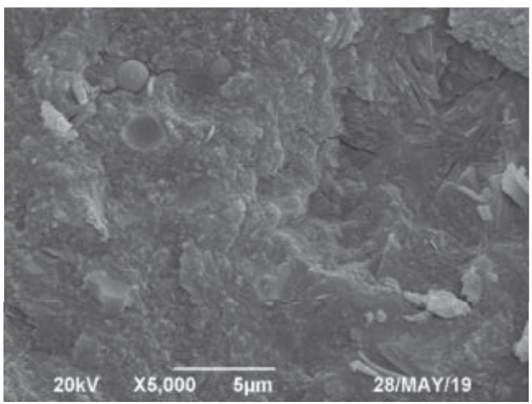

(c)
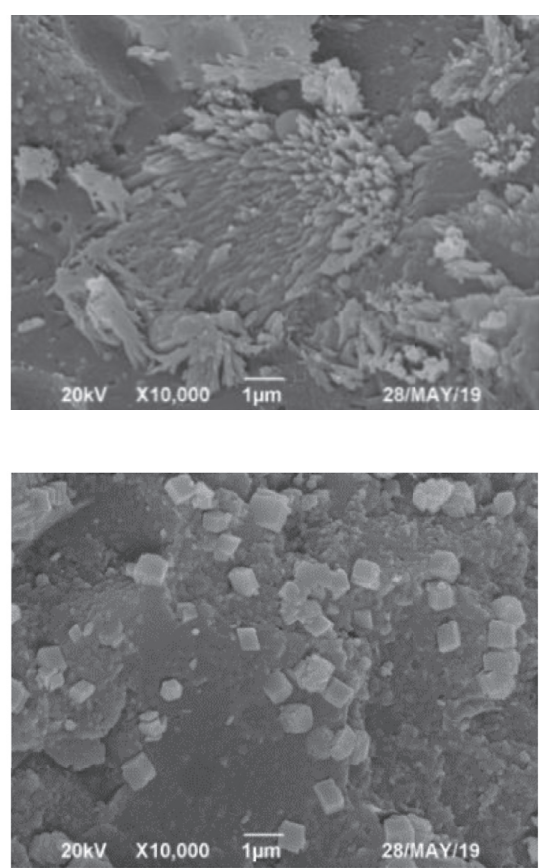

$20 \mathrm{kV} \times 10,000 \quad \overrightarrow{1 \mu \mathrm{m}}$

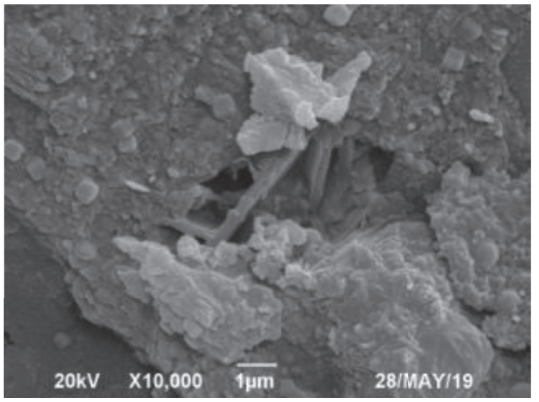

$20 \mathrm{kV} \times 10,000 \quad \frac{1}{1 \mu \mathrm{m}}$

Figure 7: FC microstructures under SEM: (a) 5\% SF; (b) 15\% SF; (c) 25\% SF.

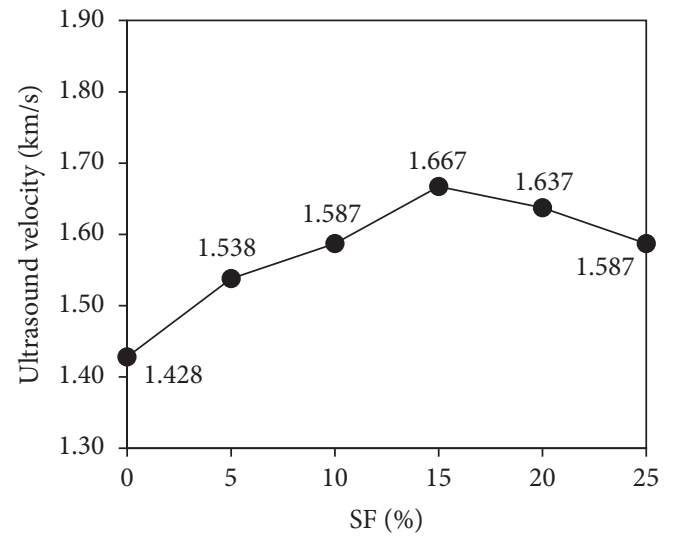

(a)

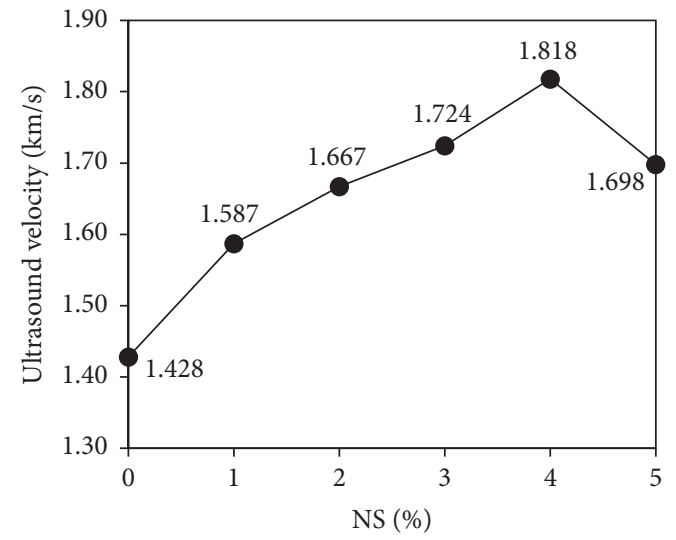

(b)

Figure 8: FC velocity. 
featured with smaller pores, fewer unhydrated particles, denser ettringite, and more C-S-H gel. FC with $4 \%$ NS had a more efficient and stronger microstructure compared to FC with $15 \% \mathrm{SF}$.

(5) FC ultrasonic speed correlated with strength. FC with $4 \%$ NS had a faster ultrasonic speed than FC with $15 \%$ SF.

\section{Data Availability}

The data used to support the findings of this study are available from the corresponding author upon request.

\section{Conflicts of Interest}

The authors declare that they have no conflicts of interest.

\section{References}

[1] Z. Zhang, J. L. Provis, A. Reid, and H. Wang, "Geopolymer foam concrete: an emerging material for sustainable construction," Construction and Building Materials, vol. 56, pp. 113-127, 2014.

[2] L. Chica and A. Alzate, "Cellular concrete review: new trends for application in construction," Construction and Building Materials, vol. 200, pp. 637-647, 2019.

[3] Li Tian, F. Huang, and Z. Jiang, "Effect of foaming gas and cement type on the thermal conductivity of foamed concrete," Construction and Building Materials, vol. 231, Article ID 117197, 2020.

[4] A. Raj, D. Sathyan, and K. M. Mini, "Physical and functional characteristics of foam concrete: a review," Construction and Building Materials, vol. 221, pp. 787-799, 2019.

[5] F. Oginni, "Continental application of foamed concrete technology: lessons for infrastructural development in Africa," British Journal of Applied Science \& Technology, vol. 5, no. 4, pp. 417-424, 2015.

[6] Y. H. M. Amran, N. Farzadnia, and A. A. Abang Ali, "Properties and applications of foamed concrete; a review," Construction and Building Materials, vol. 101, pp. 990-1005, 2015.

[7] E. K. K. Nambiar and K. Ramamurthy, "Influence of filler type on the properties of foam concrete," Cement and Concrete Composites, vol. 28, no. 5, pp. 475-480, 2006.

[8] E. P. Kearsley and P. J. Wainwright, "The effect of high fly ash content on the compressive strength of foamed concrete," Cement and Concrete Research, vol. 31, no. 1, pp. 105-112, 2001.

[9] E. P. Kearsley and P. J. Wainwright, "Ash content for optimum strength of foamed concrete," Cement and Concrete Research, vol. 32, no. 2, pp. 241-246, 2002.

[10] E. K. K. Nambiar and K. Ramamurthy, "Air-void characterisation of foam concrete," Cement and Concrete Research, vol. 37, no. 2, pp. 221-230, 2007.

[11] E. K. K. Nambiar and K. Ramamurthy, "Models for strength prediction of foam concrete," Materials and Structures, vol. 41, no. 2, pp. 247-254, 2008.

[12] E. K. K. Nambiar and K. Ramamurthy, "Models relating mixture composition to the density and strength of foam concrete using response surface methodology," Cement and Concrete Composites, vol. 28, no. 9, pp. 752-760, 2006.
[13] M. Jones and A. McCarthy, "Utilising unprocessed low-lime coal fly ash in foamed concrete," Fuel, vol. 84, no. 11, pp. 1398-1409, 2005.

[14] E. P. Kearsley and P. J. Wainwright, "Porosity and permeability of foamed concrete," Cement and Concrete Research, vol. 31, no. 5, pp. 805-812, 2001.

[15] T. T. Nguyen, H. H. Bui, T. D. Ngo, and G. D. Nguyen, "Experimental and numerical investigation of influence of airvoids on the compressive behaviour of foamed concrete," Materials \& Design, vol. 130, pp. 103-119, 2017.

[16] Li Hou, J. Li, and Z. Lu, "Effect of nanoparticles on foaming agent and the foamed concrete," Construction and Building Materials, vol. 227, Article ID 116698, 2019.

[17] J. He, Q. Gao, X. Song, X. Bu, and J. He, "Effect of foaming agent on physical and mechanical properties of alkali-activated slag foamed concrete," Construction and Building Materials, vol. 226, pp. 280-287, 2019.

[18] T. T. Nguyen, H. H. Bui, T. D. Ngo, G. D. Nguyen, M. U. Kreher, and F. Darve, "A micromechanical investigation for the effects of pore size and its distribution on geopolymer foam concrete under uniaxial compression," Engineering Fracture Mechanics, vol. 209, pp. 228-244, 2019.

[19] D. Falliano, D. De Domenico, G. Ricciardi, and E. Gugliandolo, "Experimental investigation on the compressive strength of foamed concrete: effect of curing conditions, cement type, foaming agent and dry density," Construction and Building Materials, vol. 165, pp. 735-749, 2018.

[20] C. Sun, Y. Zhu, J. Guo, Y. Zhang, and G. Sun, "Effects of foaming agent type on the workability, drying shrinkage, frost resistance and pore distribution of foamed concrete," Construction and Building Materials, vol. 186, pp. 833-839, 2018.

[21] C. Bing, W. Zhen, and L. Ning, "Experimental research on properties of high-strength foamed concrete," Journal of Materials in Civil Engineering, vol. 24, no. 1, pp. 113-118, 2012.

[22] M. R. Jones and A. McCarthy, "Preliminary views on the potential of foamed concrete as a structural material," Magazine of Concrete Research, vol. 57, no. 1, pp. 21-31, 2005.

[23] R. C. Valore Jr., "Cellular concretes part 2 physical properties,” ACI Journal Proceedings, vol. 50, no. 6, pp. 817-836, 1954.

[24] K. T. Wan, H. Zhu, T. Y. P. Yuen et al., "Development of low drying shrinkage foamed concrete and hygro-mechanical finite element model for prefabricated building fasçade applications," Construction and Building Materials, vol. 165, pp. 939-957, 2018.

[25] B. Raj, D. Sathyan, M. K. Madhavan, and A. Raj, "Mechanical and durability properties of hybrid fiber reinforced foam concrete," Construction and Building Materials, vol. 245, p. 118373, 2020.

[26] P. Chindaprasirt and U. Rattanasak, "Shrinkage behavior of structural foam lightweight concrete containing glycol compounds and fly ash," Materials \& Design, vol. 32, no. 2, pp. 723-727, 2011.

[27] GB/T 11969-2008, Test Methods of Autoclaved Aerated Concrete, Standards Press of China, Beijing, China, 2008.

[28] JGJ/T70-2009, Standard for Test Method of Performance on Building Mortar, China Architecture and Building Press, Beijing, China, 2009.

[29] ASTM C597-02, Standard Test Method for Pulse Velocity through Concrete, Annual Book of ASTM Standards, West Conshohocken, PA, USA, 2003.

[30] H.-L. Hu, Y.-P. Zeng, Y.-F. Xia et al., "Rapid fabrication of porous $\mathrm{Si} 3 \mathrm{~N} 4 / \mathrm{SiC}$ ceramics via nitridation of silicon powder 
with $\mathrm{ZrO} 2$ as catalyst," Ceramics International, vol. 40 , no. 5 , pp. 7579-7582, 2014.

[31] Y. Su, J. Li, C. Wu, P. Wu, and Z.-X. Li, "Influences of nanoparticles on dynamic strength of ultra-high performance concrete," Composites Part B: Engineering, vol. 91, pp. 595609, 2016.

[32] X. Xu, X. Zhang, and K. Wang, "Effect of density grade on pore structure and mechanical properties of foamed concrete," Civil Engineering, vol. 6, pp. 1094-1102, 2019.

[33] L. Su, Qi Sun, and S. Li, "Effect of mass fraction of foaming agent on the strength of fly ash concrete," Non-Metallic Mines, vol. 4, pp. 53-55, 2017.

[34] H. Z. Cui, T. Y. Lo, S. A. Memon, F. Xing, and X. Shi, "Analytical model for compressive strength, elastic modulus and peak strain of structural lightweight aggregate concrete," Construction and Building Materials, vol. 36, pp. 1036-1043, 2012.

[35] Y. Ke, A. L. Beaucour, S. Ortola, H. Dumontet, and R. Cabrillac, "Influence of volume fraction and characteristics of lightweight aggregates on the mechanical properties of concrete," Construction and Building Materials, vol. 23, no. 8, pp. 2821-2828, 2009.

[36] Y. H. Mugahed Amran, R. Alyousef, and H. Alabduljabbar, "Performance properties of structural fibred-foamed concrete," Results in Engineering, vol. 5, Article ID 100092, 2020.

[37] JGJ 51-2002, Technical Specification for Lightweight Aggregate Concrete, China Building Industry Press, Beijing, China, 2002.

[38] M. Mazloom, A. A. Ramezanianpour, and J. J. Brooks, "Effect of silica fume on mechanical properties of high-strength concrete," Cement and Concrete Composites, vol. 26, no. 4, pp. 347-357, 2004.

[39] E. Rozière, A. Loukili, R. El Hachem, and F. Grondin, "Durability of concrete exposed to leaching and external sulphate attacks," Cement and Concrete Research, vol. 39, no. 12, pp. 1188-1198, 2009.

[40] R. Siddique, "Utilization of silica fume in concrete: review of hardened properties," Resources, Conservation and Recycling, vol. 55, no. 11, pp. 923-932, 2011.

[41] Z. D. Rong, W. Sun, H. J. Xiao, and W. Wang, "Effect of silica fume and fly ash on hydration and microstructure evolution of cement based composites at low water-binder ratios," Construction and Building Materials, vol. 51, pp. 446-450, 2014.

[42] M. Khan and M. Ali, "Improvement in concrete behavior with fly ash, silica-fume and coconut fibres," Construction and Building Materials, vol. 203, pp. 174-187, 2019.

[43] J. Li, H. Xiao, and Y. Zhou, "Influence of coating recycled aggregate surface with pozzolanic powder on properties of recycled aggregate concrete," Construction and Building Materials, vol. 23, no. 3, pp. 1287-1291, 2009. 